\title{
UDPglucuronic Acid Pyrophosphatase Assay with the Aid of
}

\section{Alkaline Phosphatase}

\author{
E. PUHAKAINEN, ${ }^{a}$ A. SAARINEN ${ }^{b}$ and 0 . HÄNNINEN ${ }^{b}$
}

aDepartment of Clinical Chemistry, University Hospital of Kuopio, and ${ }^{b}$ Department of Physiology, University of Kuopio, Kuopio, Finland

A simple and sensitive method has been described for the determination of UDPglucuronic acid pyrophosphatase activity. Pyrophosphatase-free alkaline phosphatase preparation is added to the reaction mixture in order to hydrolyze the phosphate esters (UMP and $\alpha$ D-glucuronic acid 1-phosphate) produced by pyrophosphatase. The inorganic phosphate liberated is measured by a modification of Fiske and SubbaRow's method. The phosphatase coupled method is time saving, easy to perform and accurate. It can also be used for pyrophosphatase assays with other nucleotide substrates like UDPglucose, UDP- $N$-acetylglucosamine, NAD ${ }^{+}, \mathrm{NADH}, \mathrm{NADP}^{+}$and NADPH.

The presence of UDPglucuronic acid pyrophosphatase activity in hepatic microsomal fractions has been reported by a number of authors. ${ }^{1-4}$ This enzyme and $\alpha$-D-glucuronic acid 1-phosphate hydrolyzing enzymes are of importance in the production of free D-glucuronic acid needed in the biosynthesis of $\mathrm{D}$-glucaric acid,

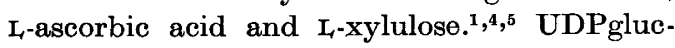
uronic acid pyrophosphatase activity is low in the liver of the guinea pig, ${ }^{4,6}$ which is unable to synthetize L-ascorbic acid. ${ }^{7}$ UDPglucuronic acid pyrophosphatase may also have a role in the control of the production of $\beta$-D-glucopyranosiduronic acids (glucuronides), since it and UDPglucuronosyltransferase share a common substrate and pyrophosphatase activity is much higher than the transferase activity, e.g. in rat liver microsomal fractions. ${ }^{5}$

In spite of the obvious importance of UDP. glucuronic acid pyrophosphatase, the enzyme and its regulation are rather poorly known, since the currently used methods in the deter- mination of UDPglucuronic acid pyrophosphatase activity are not satisfactory for routine use. The enzyme activity has been measured by determining uronic acid by the carbazole ${ }^{8}$ or naphthoresorcinol ${ }^{3,9}$ reactions after removal of unhydrolyzed UDPglucuronic acid by charcoal adsorption or by back titration methods, in which the remaining UDPglucuronic acid has been determined with the aid of UDPglucuronosyltransferase. 4,10 Also radiochemical methods have been developed for UDPglucuronic acid pyrophosphatase assay, but they are time consuming, since they require chromatography.,5 A method based on the determination of phosphate released by phosphatase has also been shortly described. ${ }^{2}$ It appears that it has been rarely used. Reasons for this have probably been the pyrophosphatase impurities in commercial alkaline phosphatase preparations and a release of endogenous phosphate from the microsomal fractions during incubation. Furthermore, problems are encountered with some methods commonly used in phosphate determinations.

In the present report we have studied in detail the conditions for the use of purified alkaline phosphatase in the determination of UDPglucuronic acid pyrophosphatase activity.

\section{EXPERIMENTAL}

A n i m a 1 s

Male albino rats (Rattus norvegicus) of Wistar/ Af/Han/Mol/(Han 67) strain were used as experimental animals. The strain was purchased five generations ago as specific pathogen-free 
from Møllegaard Avlslaboratorier A/S (Ejby, Denmark). The rats were outbred by a rotational mating system and kept under conventional circumstances in the Laboratory Animal Center of the University of Kuopio.

The rats were stunned by a blow on the head and were bled by cutting the cervical vessels. Livers were immersed in ice-cold $0.25 \mathrm{M}$ sucrose and homogenized in three volumes of cold isotonic sucrose with five strokes of a Potter-Elvehjem homogenizer (300 rpm). After a precentrifugation for $10 \mathrm{~min}$ at $10000 \mathrm{~g}$ the microsomal fraction was separated from the cytosol by centrifuging for $1 \mathrm{~h}$ at $105000 \mathrm{~g}$. The pellets were washed once and resuspended in ice-cold $0.25 \mathrm{M}$ sucrose to give about $25 \mathrm{mg}$ of microsomal protein per $\mathrm{ml}$. The protein content was determined by Lowry's method ${ }^{11}$ using bovine serum albumin as a standard.

\section{Special reagents}

Alkaline phosphatase (EC 3.1.3.1, No. 15436 Boehringer GmbH, Mannheim, Fed. Republic of Germany) purified from calf intestine was daily diluted to give an activity of $6000 \mathrm{IU} / \mathrm{l}$. Four different portions of alkaline phosphatase preparations made by Boehringer have been obtained and all of them worked satisfactorily. In preliminary studies other alkaline phosphatase preparations (No. P 3877 Sigma Chemical Co., St. Louis Mo., U.S.A. and No. 79393 Fluka AG Chemische Fabrik, Buchs, Switzerland) were also tested but they hydrolyzed UDPglucuronic acid very rapidly due to pyrophosphatase impurities.

Trichloroacetic acid-ascorbic acid reagent, ammonium heptamolybdate reagent and sodium metaarsenite-trisodium citrate reagent were prepared as described earlier. ${ }^{12}$ The chemicals used were p.a. products purchased from E. Merck AG, Darmstadt, Federal Republic of Germany.

Measurement of UDPglucuronicacid pyophosphatase act i vit $y$

UDPglucuronic acid pyrophosphatase activity was determined by measuring the production of inorganic phosphate. It was quantitated by the method of Fiske and SubbaRow as described by Baginski et al. ${ }^{12}$ with slight modifications.

The incubations were carried out at $38^{\circ} \mathrm{C}$ in a final volume of $150 \mu \mathrm{l}$ in the presence of 67 mM Tris-HCl buffer, $\mathrm{pH} \mathrm{8.9}$, containing $2 \mathrm{mM}$ UDPglucuronic acid (or other nucleotide sub. strates studied), $25 \mathrm{mM} \mathrm{MgCl}_{2}$ and $2000 \mathrm{IU} / 1$ of alkaline phosphatase. The reaction was started by adding microsomes (corresponding to about $25 \mu \mathrm{g}$ of microsomal protein) diluted in $2.5 \%$ albumin. The incubation was terminated after 5-10 min by adding $1.0 \mathrm{ml}$ of trichloro- acetic acid-ascorbic acid reagent. After spinning down the denatured proteins $(5 \mathrm{~min}$ at $5000 \mathrm{~g}$ ) the supernatants were pipetted into new tubes and $0.25 \mathrm{ml}$ of ammonium hepta-molybdate reagent was added and mixed. Thereafter 0.5 $\mathrm{ml}$ of arsenite-citrate reagent was added. The solutes were thoroughly mixed and after $15 \mathrm{~min}$ the colour was measured at $700 \mathrm{~nm}$ in a HitachiPerkin Elmer UV-Vis 139 spectrophotometer against a water blank. The measurements were carried out as duplicates and every microsome sample had its own blank lacking substrate. For every alkaline phosphatase preparation, reagent blanks were also made by omitting the micro. somes in the reaction mixture.

Potassium phosphate references $(0-2.0 \mathrm{mM})$ were used to standardize the method.

In all stages acid washed glassware was used.

\section{RESULTS}

In the beginning of the work inorganic phosphate was determined as described by Lowry and Lopez. ${ }^{13}$ This method was, however, abandoned due to instability of the colour and high absorbance in blank samples. In the method adopted the colour was stable for several hours after full development $(10-15 \mathrm{~min})$ and only traces (0.005 - 0.010 absorbance units) of colour were found in reagent blanks.

Some alkaline phosphatase preparations appeared to contain plenty of UDPglucuronic acid pyrophosphatase activity as impurity. Therefore they cannot be used for the determination of the UDPglucuronic acid pyrophosphatase in tissue samples. The preparation used also contained traces of UDPglucuronic acid pyrophosphatase activity $(2-6 \%$ of the pyrophosphatase activity in microsomes in the usual reaction mixture), but this could be eliminated by blank samples. The amount of alkaline phosphatase added to the reaction mixture (2000 IU/I) instantaneously hydrolyzed $\alpha$-Dglucuronic acid 1-phosphate and uridine monophosphate produced by UDPglucuronic acid pyrophosphatase under the conditions used. According to calculations, the phosphate esters produced during a 10 min incubation with microsomes were split in about a couple of seconds.

The production of inorganic phosphate in the reaction mixture was linearly proportional to the incubation time in the method described (Fig. 1A). Due to the high sensitivity of the method, highly diluted microsomal samples

Acta Chem. Scand. B 31 (1977) No. 2 


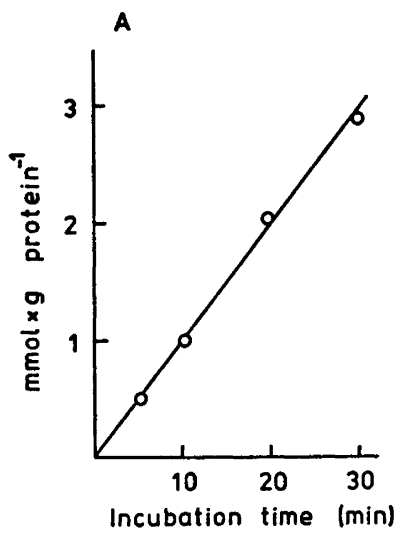

D

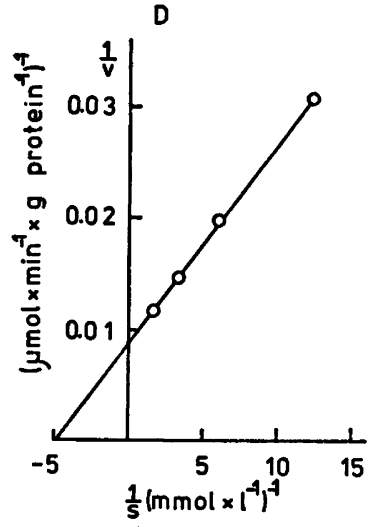

could be used as enzyme source. The dilution of microsomes also diminished the background release of endogenous phosphate from microsomes to the reaction mixture [up to $10 \mu \mathrm{mol}$ $\mathrm{min}^{-1}$ (g protein $)^{-1}$. Added alkaline phosphatase appeared to increase the hydrolysis of microsomal phosphate esters. Of the diluting media used $2.5 \%$ albumin gave the best linearity with dilution factor. If $0.15 \mathrm{M} \mathrm{KCl}$ or $0.25 \mathrm{M}$ sucrose were used, a slight autoactivation was found upon dilution. The cytosol and also denatured microsomes were unsuitable as diluting media, since they contained much phosphate and its esters and produced an intense background colour.

The recovery and precision of the method described was tested by adding different amounts of potassium dihydrogen phosphate (the final concentrations being up to $1.5 \mathrm{mM}$ ) to the reaction mixture after incubation. It was found that the increase in the intensity of the

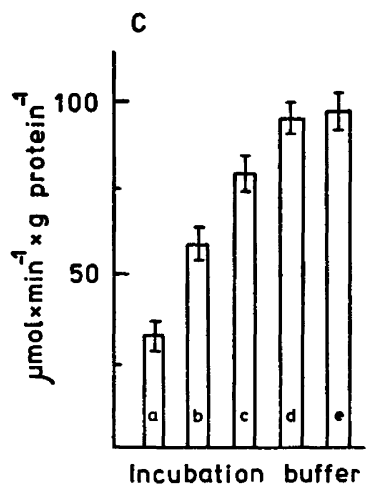

Fig. 1. The effect of incubation time on the hydrolysis of UDPglucuronic acid in the method described (Panel A) and the effect of $\mathrm{MgCl}_{2}$ concentration on the microsomal UDPgluc. uronic acid pyrophosphatase activity in $67 \mathrm{mM}$ Tris-HCl buffer, pH 8.9 (Panel B). The activity found in the presence of $2.5 \mathrm{mM}$ EDTA and absence of added $\mathrm{MgCl}_{2}$ is indicated by an arrow. In Panel $\mathrm{C}$ the effect of different buffers (67 $\mathrm{mM}, \mathrm{pH} 8.9$ ) containing $25 \mathrm{mM} \mathrm{MgCl}_{2}$ on UDPglucuronic acid pyrophosphatase activity has been depicted ( $\mathrm{a}=$ sodium borate, $\mathrm{b}=$ glycine- $\mathrm{NaOH}, \mathrm{c}=$ sodium $5^{\prime}, 5^{\prime}$-diethylbarbiturate; $d=$ diethanolamine and $\Theta=$ Tris- $\mathrm{HCl}$ ). Panel D is a Lineweaver-Burk plot of the hydrolysis of UDPglucuronic acid by rat liver microsomes in Tris- $\mathrm{HCl}$ buffer $(67 \mathrm{mM}, \mathrm{pH}$ 8.9) containing $25 \mathrm{mM} \mathrm{MgCl}{ }_{2}$.

developed colour was linearly proportional to the amount of phosphate added. The accuracy of the method was tested by measuring absorbance of 25 samples. The mean was $0.665 \pm$ 0.0098 ( \pm S.D.) absorbance units and the variation coefficient $1.5 \%$.

The $\mathrm{pH}$ optimum of UDPglucuronic acid pyrophosphatase was found to be 8.9. The optimal concentration of $\mathrm{MgCl}_{2}$ was $25 \mathrm{mM}$ (Fig. 1B). The chelator EDTA was a powerful inhibitor of the production of inorganic phosphate from UDPglucuronic acid in the method used. It inhibited both microsomal pyrophosphatase and alkaline phosphatase used as reagent (Fig. 1B).

The measurable activity of UDPglucuronic acid pyrophosphatase was found to be markedly dependent on the buffer in the reaction mixture. The highest activities 96.2 and $94.1 \mu \mathrm{mol} \alpha$-Dglucuronic acid 1-phosphate produced $\mathrm{min}^{-1}$ (g protein $)^{-1}$ were measured at optimal $\mathrm{pH}$ and

Acta Chem. Scand. B 31 (1977) No. 2 
$\mathrm{MgCl}_{\mathbf{2}}$ concentration in Tris- $\mathrm{HCl}$ and diethanolamine buffers, respectively. The activities were lower in other buffers tested (sodium $5^{\prime}, 5^{\prime}$ diethylbarbiturate, glycine- $\mathrm{NaOH}$ and sodium borate) (Fig. IC). The amount of alkaline phosphatase was not limiting the reaction rate either in Tris-HCl or sodium borate buffers, in which the highest and lowest activities were measured.

A $K \mathrm{~m}$ value of $0.21 \mathrm{mM}$ was determined for

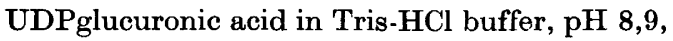
containing $25 \mathrm{mM} \mathrm{MgCl}{ }_{2}$ by the method described, when rat liver microsomes were used as enzyme source (Fig. 1D). A slight substrate inhibition was observed if UDPglucuronic acid concentrations higher than $2 \mathrm{mM}$ were used.

UDPglucuronosyltransferase is often measured in the presence of surfactants which enhance the transferase activity manifold. Therefore the UDPglucuronic acid pyrophosphatase assay was studied also under these conditions. Results obtained indicate that surfactants Triton X-100 and sodium deoxycholate (up to a concentration of $2 \%$ ) do not disturb the assay and the method developed can be successfully used in measurements of UDPglucuronic acid pyrophosphatase activity in their presence. These surfactants appeared to increase the measurable UDPglucuronic acid pyrophosphatase activity up to $2-3$-fold.

In addition to UDPglucuronic acid, a number of other nucleotides could be used as pyrophosphatase substrates in the method described. The relative hydrolysis of UDPglucuronic acid, UDPglucose,UDP- $N$-acetylglucosamine, $\mathrm{NAD}^{+}$, NADH, NADP + , and NADPH have been listed in Table 1. It appears that rat liver microsomes hydrolyze UDPglucuronic acid most efficiently.

\section{DISCUSSION}

The use of alkaline phosphatase in the determination of UDPglucuronic acid pyrophosphataso activity has been studied. Such nucleotide hydrolyzing activity can be found, e.g., in liver nuclei, ${ }^{2}$ microsomes, ${ }^{3,14}$ and plasma membranes. ${ }^{14,15}$ The method described does not need two successive incubations as do the back titration methods commonly used in UDPglucuronic acid pyrophosphatase assays. ${ }^{4,10}$ Also standardization with inorganic phosphate is easier and more accurate to perform than with the substrate UDPglucuronic acid in these methods. The radiochemical methods require labeled substrate and they are expensive and time consuming in routine work. In the methods based on the condensation reaction of carbazole ${ }^{8}$ or naphthoresorcinol ${ }^{3,8}$ with uronic acid and the acid hydrolysis of D-glucuronic acid 1phosphate it means extra steps. The sensitivity of these procedures is also poorer than that of the method described here. Two mol of inorganic phosphate are produced from one mol of UDP. glucuronic acid, which increases the sensitivity.

The UDPglucuronic acid pyrophosphatase activities obtained in the present study are in rather good agreement with results reported earlier in the literature. In our experiments the enzyme activity in rat liver microsomes was 96.2 $\pm 5.0 \mu \mathrm{mol} \alpha$-D-glucuronic acid 1-phosphate produced $\min ^{-1}$ (g microsomal protein $)^{-1}$ in Tris-HCl buffer, $\mathrm{pH}$ 8.9. Ogawa et al. ${ }^{3}$ have

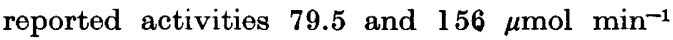
(g protein $)^{-1}$ using the method based on the measurement of nucleotide-free glucuronic acid. Lau and Wong ${ }^{16}$ have found an activity of $58.3 \mu \mathrm{mol} \mathrm{min}^{-1}$ (g protein $)^{-1}$ in veronal buffer, pH 9.4, using the back titration method and harmol as glucuronic acid acceptor in subsequent glucuronidation. In veronal buffer the method described here gave an activity of 79

Table 1. The relative hydrolysis of different nucleotides by microsomal UDPglucuronic acid pyrophosphatase in $67 \mathrm{mM}$ Tris-HCl buffer, pH 8.9, containing $25 \mathrm{mM} \mathrm{MgCl}_{2}$ as measured by the phosphatase coupled method and compared to the activities reported by Ogawa et al. ${ }^{3}$ The value 100 in the present method corresponds to the activity of $96 \mu \mathrm{mol} \alpha-\mathrm{D}$-glucuronic acid 1-phosphate produced $\min ^{-1}(\mathrm{~g} \text { protein })^{-1}$.

\begin{tabular}{llc}
\hline Substrate & $\begin{array}{l}\text { Relative } \\
\text { hydrolysis. } \\
\text { Present } \\
\text { method }\end{array}$ & $\begin{array}{c}\text { Ogawa } \\
\text { et al. }\end{array}$ \\
& & \\
\hline UDPglucuronic acid & 100 & 100 \\
UDPglucose & 85 & 88 \\
UDP-N-acetylglucos- & 78 & 71 \\
amine & 48 & 30 \\
NAD+ & 87 & 110 \\
NADH & 41 & 26 \\
NADP+ & 82 & - \\
NADPH & & \\
\hline
\end{tabular}

Acta Chem. Scand. B 31 (1977) No. 2 
$\mu \mathrm{mol} \min ^{-1}$ (g protein) $)^{-1}$. We have previously reported that a radiochemical method based on the production of ${ }^{14} \mathrm{C}$-labeled $\alpha$-D-glucuronic acid 1-phosphate from UDP $\left[\mathrm{U}^{-14} \mathrm{C}\right]$ glucuronic acid $^{5}$ gives UDPglucuronic acid pyrophosphatase activity of $72 \mu \mathrm{mol} \mathrm{min} \mathrm{min}^{-1}$ (g protein) $)^{-1}$ in 0.3 $\mathrm{M}$ Tris-HCl buffer, $\mathrm{pH}$ 8.9. The slightly higher activity found using the new method is probably due to the differences in the ion concentrations of the buffers used.

Schliselfeld et al. ${ }^{2}$ have also determined UDPglucuronic acid pyrophosphatase with the aid of phosphatase coupling, but they have obtained considerably higher UDPglucuronic acid pyrophosphatase activity [142 $\mu \mathrm{mol} \mathrm{\textrm {min } ^ { - 1 }}$ (g protein $)^{-1}$ in liver microsomes] in their experiments than observed in the present study.

In the present study it was found that pyrophosphatase is common as an impurity in alkaline phosphatase preparations and only a properly purified enzyme can be used. The release of endogenous phosphate from the microsomal membranes can also be quite considerable $\left[1-10 \mu \mathrm{mol} \mathrm{min}^{-1}(\mathrm{~g} \text { protein })^{-1}\right]$, and corrections should be made for its effect on the assay by using suitable controls. Furthermore, it appears that certain methods commonly used in phosphate determinations (e.g. Ref. 13) cannot be used in this assay. The addition of arsenite-citrate reagent stabilizes, however, the final colour. ${ }^{12}$ The phosphatase coupled method can also be used in pyrophosphatase assays with other nucleotide substrates containing a pyrophosphate bond, since a coupling of the pyrophosphatase reaction with the unspecific alkaline phosphatase reaction makes the assay widely applicable.

The activities obtained in the present study with UDPglucose and UDP- $N$-acetylglucosamine as substrates were in good agreement with the results of Ogawa et al. ${ }^{3}$ who measured the hydrolysis of UDPglucuronic acid, UDP. glucose and UDP- $N$-acetylglucosamine by a naphthoresorcinol method. It is easier to measure the hydrolysis of $\mathrm{NAD}^{+}, \mathrm{NADH}, \mathrm{NADP}+$, and NADPH by the present method than by coupling the reactions with isocitrate or alcohol dehydrogenases and by following the changes in absorption at $340 \mathrm{~nm} .^{3}$

The method described here is reproducible, easy to perform and time-saving. Furthermore, it is sensitive and applicable to the determina- tion of nucleotide pyrophosphatase activity with several substrates. It should, however, be kept in mind that the inhibition of pyrophosphatases by EDTA ${ }^{2,5,17}$ or by other chelating agents, cannot be studied with the aid of the phosphatase coupled method, because the chelators inhibit also alkaline phosphatase in the reaction mixture.

\section{REFERENCES}

1. Conney, A. H. and Burns, J. J. Biochim. Biophys. Acta 54 (1961) 369.

2. Schliselfeld, L. H., van Eys, J. and Touster, O. J. Biol. Chem. 240 (1965) 811.

3. Ogawa, H., Sawada, M. and Kawada, M. J. Biochem. (Tokyo) 59 (1966) 126.

4. Wong, K. P. and Lau, Y. K. Biochim. Biophys. Acta 220 (1970) 61 .

5. Puhakainen, E. and Hänninen, O. Eur. $J$. Biochem. 61 (1976) 165.

6. Hollmann, S. and Touster, O. Biochim. Biophys. Acta 62 (1962) 338.

7. Chatterjee, I. B., Kar, N. C., Ghosh, N. C. and Guha, B. C. Ann. N. Y. Acad. Sci. 92 (1961) 36.

8. Dische, Z. J. Biol. Chem. 167 (1947) 189.

9. Fishman, W. H. and Green, S. J. Biol. Chem. 215 (1955) 527.

10. Ginsburg, V., Weissbach, A. and Maxwell, E. S. Biochim. Biophys. Acta 28 (1958) 649.

11. Lowry, O. H., Rosebrough, N. J., Farr, A. L. and Randall, R. J. J. Biol. Chem. 193 (1951) 265.

12. Baginski, E. S., Foa, P. P. and Zak, B. In Bergmeyer H.-U., Ed., Methoden der Enzymatischen Analyse, Verlag Chemie, Weinheim 1970, 2nd Ed., Vol. 1, p. 839.

13. Lowry, O.H. and Lopez, J. A. J. Biol. Chem. 162 (1946) 421.

14. Bischoff, E., Wilkening, J., Tran-Thi, T.-A. and Decker, K. Eur. J. Biochem. 62 (1976) 279.

15. Emmelot, P., Bos., C. J., Benedetti, E. L. and Rumke, P. Biochim. Biophys. Acta 90 (1964) 126.

16. Lau, Y. K. and Wong, K. P. Biochim. Biophys. Acta 334 (1974) 431.

17. Miettinen, T. A. and Leskinen, E. Biochem. Pharmacol. 12 (1963) 565.

Received August 6, 1976.

Acta Chem. Scand. B 31 (1977) No. 2 